\title{
President's Letter
}

\author{
Anna-Maria Rollin \\ President, British Anaesthetic \& Recovery Nurses Association
}

A $S$ part of the phased implementation of the European Working Time Directive (EWTD), junior doctors' working hours were restricted to 58 hours per week as of August 2004. Junior doctors' hours have been coming down gradually for some years. When I was a junior doctor (way back before the Flood), we had 'time off', not 'time on'. This sounds like a nice distinction, but in fact, it makes an enormous difference. It represents a whole mindset. The assumption was that we were always there, day and night, except for a defined half day and a few nights each week. Alternate weekends off - if you could be spared.

I am not defending this system for a minute. It turned junior doctors (or at least some of them) into socially incompetent, exhausted, institutionalised zombies. It clearly needed to change, and it has. However, for junior doctors to limit their working hours to 58 per week, they need to work shifts. If they are there at night, they are not there during the day, and vice versa, and after a week of nights, they may not be there at all for a whole week.

What has this to do with nurses? Well, in fact, a great deal. Nurses have always worked shifts. They have always handed over to one another at the end of a shift and gone away (more often late than not, but they have gone). It was the junior doctors who provided continuity. The pre-registration house officer may not have known much medicine, but he knew his patients, and he knew the nurses. He was always there when they came and went. More often than not, in the early days of a career, it was the nurses who told him what to do, and he could do it safely because he knew all about his patients and also which nurses he could trust to give wise advice. What now?

Does any of this apply to anaesthetic and recovery nurses? After all, do they need continuity? They look after patients during the most acute phases of their illness, for short periods of time. What does it matter to them whether or not the junior doctors know the patients in their care?
In reality, it matters to this group of nurses more than most, for the very reason that they only have very short term care of their patients. If a problem develops in the post-anaesthetic care unit, it is very helpful to be able to call on a doctor who knows the patient, who knows what the pre-operative state was, and can give relevant advice based on familiarity with that particular individual.

We will have to develop mechanisms to compensate for shift working. One crucial lesson to be learned from nurses, as experienced shift workers, is the importance of proper, detailed hand-over. How many times have I been on the ward only to discover that the nurses are in report'? This, the holy of holies, is interrupted at one's peril. Everything stops, everything waits, nothing moves. No sensible patient dares to arrest during report; no doctor with the slightest sense of self-preservation sticks his head in; and quite right too. All the evidence shows that for shift systems to work safely there must be meticulous hand-over of care, patient by patient, with up to date details of current condition and current problems. It takes time; it also makes a difference. Doctors are bad at this; they will have to learn.

Before I am accused of undue sycophancy, there are some things we must not learn from nurses. There is nothing more annoying, when asking a question of the nurse looking after the patient, than being told 'I was off', as if that negates the relevance of everything that happened during that time. It's happening to junior doctors, too. 'I was off'. 'Someone else took the bloods'. 'Someone else booked the bed' (which usually means, of course, that no one else did). It would be a great help to patients (not to mention my temper) if both lots of professionals gave up this particular excuse.

A useful new development is that of multidisciplinary notes. The paperless, electronic patient record is, sadly, still some way off, so we are stuck with the old unwieldy folders for a while yet. Traditionally, nurses have made one set of notes, doctors another. Physiotherapists, 
occupational therapists, pharmacists, Uncle Tom Cobbley and all, have had their own segregated sections, read only by their coevals. The hazards of the system are obvious. It's not about communication but about tick-boxing. The only thing that held the system together was the fact that both staff and patients were around for a lot longer, and got to know one another, so that there was a sort of collective intelligence.
Most modern patient records are designed so that everybody writes in one record, and the story unfolds in chronological order. If we develop this system properly, we will have overcome one of the major hazards of shift working. The patient will become not 'nobody's', but 'everybody's'. 